\title{
How Do Nutrition Guidelines Compare for Industry to Market Food and Beverage Products to Children? World Health Organization Nutrient Profile Standards versus the US Children's Food and Beverage Advertising Initiative
}

\author{
Margo G. Wootan, DSc,' Jessica Almy, JD,' Maciel Ugalde, PhD, MS, RDN, ${ }^{2}$ and Molly Kaminski ${ }^{3}$
}

\section{Abstract}

Background: Food and beverage advertising targeting children influences their food choices, diets, and health. Experts have suggested that efforts on food marketing to children would be more effective if self-regulatory nutrition criteria were stronger. The US self-regulatory program, the Children's Food and Beverage Advertising Initiative (CFBAI), and the World Health Organization (WHO) Europe nutrient profile model use different approaches to set nutrition criteria for food marketing to children, making comparing the strength of their criteria challenging.

Methods: We compared the number and percentage of foods and beverages that met the 2014 CFBAI Category-Specific Uniform Nutrition Criteria with the WHO European nutrient profiling criteria for food and beverage marketing to children.

Results: The June 2015 CFBAI product list included 185 food items and 34 multicomponent meals that could be advertised to children 11 years and younger. Among individual food items $(n=185), 44 \%(n=82)$ were products in categories that were not permitted to be marketed to children according to WHO criteria. Almost half of the products $(49 \%, n=50)$ exceeded sweetener levels, 25\% $(n=26)$ exceeded sodium levels, and 6\% $(n=6)$ exceeded calories. Of the 34 multicomponent children's meals permissible under CFBAI, only two met WHO criteria.

Conclusions: Overall, $85 \%$ of the food and beverage items and meals that the CFBAI and its member companies considered to be acceptable to market to children could not be marketed to children under the WHO model. CFBAI should strengthen its nutrition criteria to more effectively reduce unhealthy food marketing to children.

Keywords: children; food marketing; nutrition; policy; WHO

\section{Introduction}

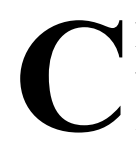

hildhood obesity is a major public health concern in the United States. In 2015-2016, 35\% of children 2-19 years old were overweight or obese. ${ }^{1}$ Food and beverage advertising targeting children contributes to increased obesity rates by promoting calorie-dense lownutrient foods and sugared beverages and influencing children's food choices, diet, and health. ${ }^{2}$ In 2009, 48 companies spent $\$ 1.8$ billion to promote food and beverages to children and teens in the United States. ${ }^{3}$ For marketing to children in the United States, food companies spend the most on television, followed by internetmediated marketing and, to a lesser extent, school-based marketing, mobile phone messaging, magazines and other forms of print, free samples and gifts, and packaging. ${ }^{3,4}$

In 2006, the Council of Better Business Bureaus launched the Children's Food and Beverage Advertising

'Center for Science in the Public Interest, Washington, DC.

${ }^{2}$ Department of Food, Nutrition, and Packaging Services, Clemson University, Clemson, SC.

${ }^{3}$ Recipe for Success Foundation, Houston, TX. 
Table I. Children's Food and Beverage Advertising Initiative Company Participant List (At Time of Analysis, June 2015)
I. American Licorice Company ${ }^{a}$
10. Kellogg Company
2. Burger King Corporation
II. Kraft Food Group, Inc.
3. Campbell Soup Company
12. Mars, Inc. ${ }^{a}$
4. The Coca-Cola Company ${ }^{a}$
13. McDonald's USA
5. ConAgra Foods, Inc.
6. Danone North America, PBC
7. Ferrero USA, Inc. ${ }^{a}$
8. General Mills, Inc.
9. The Hershey Company
14. Mondolez Global LLC
15. Nestlé USA
16. PepsiCo, Inc.
17. Post Foods, LLC
18. Unilever USA

${ }^{a}$ Not engaging in child-directed advertising (as per CFBAl definition of advertising).

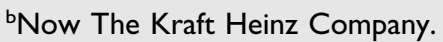

Initiative (CFBAI). The initiative is a voluntary selfregulation program with the goal of shifting the mix of food advertised to children 11 and under to healthier options. ${ }^{5}$ Initially, the initiative was comprised of 10 companies. It has grown to 18 companies since then (Table 1), representing about $80 \%$ of advertising during children's television programming. ${ }^{5}$

Six CFBAI companies do not engage in child-directed advertising (as per the CFBAI definition of advertising). ${ }^{6}$ The 12 other participants limit advertising to products that meet CFBAI Category-Specific Uniform Nutrition Criteria. ${ }^{6}$ Currently, the criteria are specific to 10 categories of food: juices; dairy products (with subcategories for milk, yogurt, dairy desserts, and cheese); grains, fruits, vegetables, and others; soups and meal sauces; seeds, nuts, and nut butters; meat and fish; mixed dishes; main dishes; small meals; and meals. In addition, sugarsweetened beverages are limited to no more than 40 calories per serving. CFBAI criteria are based on serving size and provide limits for calories, saturated fat, sodium, and total sugar. ${ }^{7}$ In January 2020, CFBAI will implement updated nutrition criteria, which expand the number of food categories, will use added rather than total sugar criterion, and will make incremental improvements to the limits for sodium and added sugars. ${ }^{8}$

As part of the Vienna Declaration on Nutrition and Noncommunicable Diseases in the Context of Health 2020, the World Health Organization (WHO) Regional Office for Europe developed a nutrient profile model to take "decisive action to reduce the food marketing pressure on children with regard to foods high in energy, saturated fats, trans fatty acids, free sugars, or salt." 9 This tool was designed to be used or adapted by member states across Europe on a voluntary basis, taking into account individual national circumstances. The model sets food category- specific thresholds for total fat, saturated fat, total sugar, added sugars, salt, energy (calories), and nonsugar sweeteners that vary across the 17 food categories, with limits on some nutrients (e.g., fat) applying to most categories and others (e.g., nonsugar sweeteners) applying only to a few categories. ${ }^{9}$ Marketing of candy, sweet baked goods, juices, energy drinks, and ice creams/frozen desserts is not permitted. ${ }^{9}$

The purpose of this study is to compare the nutrition criteria for restricting marketing of unhealthy foods to children used by the majority of food companies in the United States ${ }^{7}$ and the WHO Europe nutrient profile model. ${ }^{9}$ When the WHO announced the Europe nutrient profile model to address food marketing to children, we found it difficult to compare those standards with the CFBAI nutrition criteria to assess their relative strength in addressing food marketing to children. Both CFBAI and WHO approaches use nutrient profiling to determine if foods and beverages should be advertised to children. However, comparisons between the different approaches were challenging because of differences in the categories used and the portion sizes on which nutrient standards are based. Thus, we compared the nutrition standards by assessing whether foods and beverages on the June 2015 CFBAI list of compliant products, which met its nutrition criteria, would meet the voluntary WHO model for products permissible to advertise to children in Europe.

\section{Methods}

This study put products that met the CFBAI nutritional criteria through the WHO Europe nutrient profile model as a means of comparing the two approaches addressing unhealthy food marketing to children. Nutrition information (calories, total fat, saturated fat, sodium, sugar, and nonsugar sweeteners) was obtained from company websites for foods, beverages, and meals listed on the June 2015 CFBAI product list (i.e., items that met the CFBAI nutrition criteria as of June 2015 and could appear in advertising directed to children 11 years old and younger). ${ }^{6}$ Nutrition information was calculated per 100 grams of product. Where nutrition information was unavailable, we called or e-mailed the company or collected the information from the product label. All products on the June 2015 list were analyzed regardless of whether they were discontinued by the time this study was completed.

CFBAI products were assessed on the basis of the WHO Europe nutrient profile model. ${ }^{9}$ Products were categorized as per WHO definitions. ${ }^{9}$ Multicomponent meals were analyzed and compared separately from individual food and beverage items, given that they are treated differently in the WHO model; all items in a meal must individually meet relevant WHO nutrition criteria. Where nutrition information for components of the meals was available, it was analyzed to determine whether the components met the WHO nutrition profiling model. Where a company did not provide nutrition information for component parts, the meal was assessed only as to whether any of the items 
included were in a prohibited category. Eight beverage varieties were listed on the CFBAI product list as a single product, but in parentheses, it was noted that the product came in multiple flavors [e.g., "Capri Sun Super V Fruit and Vegetable Juice Drink Blend (all flavors)"']. Given that the companies listed these as single products on the CFBAI product list and the nutrition profile for each was similar (not different enough to affect if it met the WHO criteria), we counted each of these as single products for our analyses (e.g., Capri Sun Super V Fruit and Vegetable Juice Drink Blend was counted as one product, not three-Berry Carrot, Apple Sweet Potato, and Punch Carrot).

If all varieties in a product line were listed separately on the CFBAI product list, they were counted as separate products, but if they were listed together (in parentheses after the product name, e.g.), we counted them as a single product.

Given the absence of an added sugar disclosure on most US nutrition facts panels (which goes into effect for large companies in January 2020), in categories where the WHO model prohibits added sugars (3-savoury snacks, 4b-milk drinks, 4d-other beverages, 16-processed fruits, vegetables, and legumes, and 17-sauces, dips, and dressings), we attempted to ascertain if a product's sugar was added or not. We assessed the ingredient label for sugar (e.g., sugar, dried cane juice, fructose, and corn syrup). If a type of sugar was listed as an ingredient, the product was considered to contain added sugars. If a product contained no fruit or dairy ingredients, total sugar was used as the value for added sugars. For products that contained dairy or fruits, we estimated the amount of naturally occurring sugar by identifying the total sugar contained in the same quantity of the unsweetened plain variety of the same product. Where the brand did not carry an unsweetened variety of the same product, we used the USDA National Nutrient Database for Standard Reference. ${ }^{10} \mathrm{We}$ subtracted this amount of naturally occurring sugar from the total sugar listed on the company website or product label. If we were unable to estimate how much of the sugar was added, the total amount of sugar was used.

\section{Results}

The 2015 CFBAI product list included 185 individual food and beverage products and 34 multicomponent kids' meals that were identified by CFBAI-participating companies as meeting CFBAI Category-Specific Uniform Nutrition Criteria (and thus eligible to market to children 11 years and younger). ${ }^{6}$

\section{Individual Products}

The CFBAI-approved products were in the following WHO food categories: $21 \%(n=38)$ of the products were cakes, sweet biscuits, and pastries; $18 \%(n=34)$ were breakfast cereals; and 14\% $(n=26)$ were chocolate and sugar confectionery, energy bars, and sweet toppings and desserts (Table 2). No individual products on the CFBAI

\begin{tabular}{|c|c|c|}
\hline Category & $\begin{array}{c}\text { No of } \\
\text { products }\end{array}$ & Percentage \\
\hline $\begin{array}{l}\text { Cakes, sweet biscuits, and pastries; } \\
\text { other sweets, bakery wares, } \\
\text { and dry mixes for making such }\end{array}$ & 38 & 21 \\
\hline Breakfast cereals & 34 & 18 \\
\hline $\begin{array}{l}\text { Chocolate and sugar confectionery, } \\
\text { energy bars, and sweet toppings } \\
\text { and desserts }\end{array}$ & 26 & 14 \\
\hline $\begin{array}{l}\text { Yogurts, sour milk, cream, } \\
\text { and other similar foods }\end{array}$ & 23 & 12 \\
\hline $\begin{array}{l}\text { Ready-made/convenience } \\
\text { foods and composite dishes }\end{array}$ & 22 & 12 \\
\hline Edible ices & 16 & 9 \\
\hline Savory snacks & 13 & 7 \\
\hline Beverages & 8 & 4 \\
\hline Cheese & 5 & 3 \\
\hline Totals & 185 & 100 \\
\hline
\end{tabular}

No individual products on the CFBAI list fell into the following food WHO categories: butter and other fats; bread and bread products; fresh or dried pasta or rice; fresh/frozen meat or poultry; fresh/ frozen fruits and vegetables; processed fruits and vegetables; or sauces, dips, and dressings. Some meal combinations (discussed below) did contain components in one or more of these categories.

CFBAI, Children's Food and Beverage Advertising Initiative; WHO, World Health Organization.

food marketing to children list fell into the WHO categories for fresh and frozen fruits and vegetables or processed fruits and vegetables. However, some meal combinations did contain foods in these categories.

Marketing to children was not permitted for five WHO categories: chocolate and sugar confectionery; cakes, sweet biscuits, and pastries; juices; energy drinks; and edible ices. Thus, for those categories, nutrient criteria were not specified. Of CFBAI-listed individual food items, $44 \%(n=82)$ were in categories that would not be permitted to be marketed to children as per the WHO nutrition criteria.

Nutrient standards were applied to each of the remaining categories. Among the products in these categories $(n=103), 71 \%(n=73)$ exceeded at least one of the nutrient limits for fats, sweeteners, sodium, or calories. Not all categories had limits for each nutrient. None of the products in categories subject to limits on total fat or saturated fat $(n=84)$ exceeded either limit. However, almost half $(n=50)$ of the products in categories with limits on total sugar or a prohibition on added sugars or nonsugar sweeteners failed 


\begin{tabular}{|c|c|c|c|c|c|c|c|}
\hline \multirow[b]{2}{*}{ Category } & \multirow{2}{*}{$\begin{array}{l}\text { No. of } \\
\text { products }\end{array}$} & \multicolumn{2}{|c|}{$\begin{array}{l}\text { Exceeded WHO } \\
\text { sweetener limits }\end{array}$} & \multicolumn{2}{|c|}{$\begin{array}{l}\text { Exceeded WHO } \\
\text { sodium limits }\end{array}$} & \multicolumn{2}{|c|}{$\begin{array}{l}\text { Exceeded WHO } \\
\text { calorie limits }\end{array}$} \\
\hline & & $n$ & $\%$ & $n$ & $\%$ & $n$ & $\%$ \\
\hline Savory snacks & 13 & 1 & 8 & 13 & 100 & $\mathrm{~N} / \mathrm{A}$ & $\mathrm{N} / \mathrm{A}$ \\
\hline Beverages & 6 & 6 & 100 & N/A & N/A & N/A & N/A \\
\hline Breakfast cereals & 34 & 29 & 85 & 2 & 6 & $\mathrm{~N} / \mathrm{A}$ & $\mathrm{N} / \mathrm{A}$ \\
\hline Yogurts and similar foods & 23 & 13 & 57 & 0 & 0 & $\mathrm{~N} / \mathrm{A}$ & $\mathrm{N} / \mathrm{A}$ \\
\hline Cheese & 5 & N/A & $\mathrm{N} / \mathrm{A}$ & 5 & 100 & $\mathrm{~N} / \mathrm{A}$ & $\mathrm{N} / \mathrm{A}$ \\
\hline Ready-made/convenience foods & 22 & I & 5 & 6 & 27 & 6 & 27 \\
\hline Totals & 103 & 50 & 49 & 26 & 25 & 6 & 6 \\
\hline
\end{tabular}

No product exceeded WHO total or saturated fat limits.

${ }^{a}$ The categories of cakes, sweet biscuits, and pastries, other sweets, bakery wares, and dry mixes for making such; chocolate and sugar confectionery, energy bars, and sweet toppings and desserts; and edible ices are not included in this table since those categories are not permitted to be marketed under the WHO model, and thus, nutrient criteria were not specified for them.

${ }^{b}$ This column encompasses all limits or prohibitions on sweeteners. Savory snacks and beverages were subject to a prohibition on added sugars; breakfast cereals, yogurts, and ready-made food categories had a total sugar limit. Beverages also could not contain nonsugar sweeteners.

the WHO criteria in these categories. About one-quarter $(n=26)$ of products in categories that limited sodium exceeded those limits (Table 3).

Of the total individual products approved for marketing through CFBAI $(n=185)$, only $16 \%(n=30)$ met the nutrition criteria of the WHO model. Most of the foods that met WHO criteria were ready-made and convenience foods and composite dishes $(9 \%, n=16$; all were canned pasta), followed by yogurts and yogurt drinks $(5 \%, n=10)$ and breakfast cereals $(2 \%, n=4)$.

\section{Multicomponent Kids' Meals}

Four CFBAI companies offered a total of 34 multicomponent products, namely restaurant children's meals (from McDonald's and Burger King) and prepackaged meal packs (Kraft Heinz) and frozen dinners (Conagra Brands). These were analyzed separately in accordance with WHO guidelines, which state that all items in a meal must individually meet relevant nutrition criteria. ${ }^{9}$ Only 2 of the 34 meals met WHO criteria.

Seventy-one percent of the CFBAI-approved meals $(n=24)$ contained foods or beverages not permitted under the WHO model, such as juices, cakes, or confectionery. However, an equal number of meals $(n=24)$ contained fresh and frozen fruits, vegetables, and legumes, such as apple slices, corn, and mandarin oranges. There was overlap between meals that contained components from those categories. Among meals that did not contain items from impermissible food or beverage categories $(n=10), 80 \%$ exceeded fat, added sugars, or other nutrient limits, primarily due to inclusion of french fries $(n=7)$ and/or chocolate milk $(n=4)$.

\section{Discussion}

Industry self-regulation is a positive step toward limiting marketing of unhealthy food and beverages to children. However, several studies show that the majority of products advertised to children in the United States continue to be of poor nutritional value. ${ }^{11,12}$ For example, a study of Nickelodeon's advertising found that the percent of food advertisements that are for foods of poor nutritional value decreased from $88 \%$ in 2005 to $65 \%$ in $2015 .{ }^{13}$ While this reduction is encouraging, advocates have suggested that efforts on food marketing to children would be more effective if self-regulatory nutrition standards were stronger.

This study found that $85 \%$ of the food and beverage items and meals that the CFBAI and its member companies consider to be permissible to market to children 11 years and younger could not be marketed to children under the WHO model. Similarly, a study that classified CFBAIlisted products into Go, Slow, and Whoa foods using National Institutes of Health standards found that $69 \%$ of CFBAI-listed products were classified as Whoa foods, that is, foods high in calories and low in nutrients. ${ }^{14}$

Based on the proportion of products that meet CFBAI nutrition criteria, but fail WHO criteria, we conclude that criteria for WHO recommendations are more rigorous. Almost a quarter of the food products on the CFBAI list exceeded WHO criteria for sweeteners (including caloric and noncaloric). Most of the products that exceeded sweetener limits were breakfast cereals and yogurts. CFBAI allows 10 grams of sugar in one serving of cereal. In comparison, federal standards for eligible foods for the Special Supplemental Nutrition Program for Woman, 
Infants, and Children are no more than 6 grams of sugar per dry ounce of cereal. ${ }^{15}$

According to the 2015 Dietary Guidelines for Americans, intake of added sugars is high among children and adolescents. ${ }^{16}$ The guidelines indicate that healthy eating patterns limit added sugars to less than $10 \%$ of calories per day. Major sources of added sugars in the American diet include soda and other sugary beverages; grain-based and frozen desserts; and candies, jams, syrups, and sweet toppings. ${ }^{16}$ Those food categories are not allowed to be marketed to children under the WHO model.

The WHO model is also stronger in limiting sodium in foods promoted to children. CFBAI standard limits vary from 110 to $740 \mathrm{mg}$ per serving or meal, while the WHO model limits many categories at levels ranging from 40 to $680 \mathrm{mg}$ per 100 grams of food. This means, for example, that Pepperidge Farm cheddar goldfish crackers, which have $270 \mathrm{mg}$ of sodium per 30-gram serving $(900 \mathrm{mg} / 100$ grams of crackers), meet the CFBAI standard, but exceed the WHO limit, which is $100 \mathrm{mg}$ per 100 grams of food for savory snacks. Most sodium consumed by Americans comes from salt added by food manufacturers and restaurants, with little coming from salt added in home cooking and at the table. ${ }^{17}$ Eating more sodium is associated with increased blood pressure in children and adolescents, and the effect is greater in overweight and obese children and adolescents. ${ }^{18}$ High blood pressure in childhood often leads to high blood pressure in adulthood and is linked to early development of heart disease and stroke. ${ }^{19}$

The WHO model only permits meals in which all components of the meal meet the calorie and nutrient limits in the food-specific categories for those components. In contrast, CFBAI-compliant meals can contain foods of low nutritional quality (e.g., fries, hamburgers, and sugary drinks) as long as the whole meal meets standards.

Another notable difference between the WHO model and CFBAI criteria is that unlike CFBAI standards, the WHO approach does not explicitly require that foods and beverages advertised to children make a positive contribution to children's diets through inclusion of essential nutrients (e.g., calcium, fiber, potassium, and vitamin D) or by containing meaningful amounts of fruits, vegetables, or whole grains. A limitation of this study is that no comparisons were made regarding the presence of essential nutrients or key food groups between foods allowed to be marketed to children using either of the standards. However, the WHO model does not allow for marketing of several categories of nutrition-poor foods, such as candy, sweet baked goods, and ice cream.

Findings of this study suggest that CFBAI nutrition standards for food marketing to children are weaker than WHO criteria in many respects. An expert panel convened by the Robert Wood Johnson Foundation's Healthy Eating Research national program found that CFBAI nutrition standards for food marketing to children were weaker than eight other sets of nutrition standards they assessed, finding that they had some inconsistencies with the Dietary
Guidelines, allowed some products to qualify based on nutrients alone rather than servings of key food groups, included exemptions, and did not set strong enough limits for undesirable nutrients and food components. ${ }^{20}$

In September 2018, CFBAI announced updates to its nutrition criteria, which will go into effect in January $2020{ }^{8}$ Those updates make progress on some of the concerns raised by this analysis, including incremental improvements on sodium and added sugars. For example, sodium limits are reduced by $14 \%$ for breads, $10 \%$ for savory snacks, and $5 \%$ for mixed dishes. However, the updated CFBAI limit of $260 \mathrm{mg}$ per serving for savory snacks is well above the limit ( $200 \mathrm{mg} /$ package) set by the US Department of Agriculture for Smart Snacks in school. ${ }^{21}$

CFBAI should continue to make improvements to strengthen its nutrition criteria for food marketing to children to bring them into greater alignment with the Dietary Guidelines for Americans and look to the WHO model for ways to improve them by further strengthening criteria for added sugars and sodium and excluding categories such as candy, sweet baked goods, and frozen desserts from marketing to children. The update of the Dietary Guidelines due out in 2020 will provide another opportunity for CFBAI to revisit and strengthen its standards for marketing to children.

\section{Acknowledgments}

The authors thank Molly Kaminski and the Recipe for Success Foundation for their support of the study. Funding for the study was provided out of general funds of the Center for Science in the Public Interest.

\section{Author Disclosure Statement}

No competing financial interests exist.

\section{References}

1. Fryar CD, Carroll MD, Ogden CL. Prevalence of Overweight, Obesity, and Severe Obesity Among Children and Adolescents Aged 2-19 Years: United States, 1963-1965 Through 2015-2016. Atlanta, GA: National Center for Health Statistics, Centers for Disease Control and Prevention. September 2018. Available at https://www.cdc.gov/nchs/data/hestat/obesity_child_15_16/obesity_ child_15_16.pdf Last accessed December 16, 2018.

2. McGinnis JM, Gootman JA, Kraak VI (eds). Food Marketing to Children and Youth: Threat or Opportunity? Washington, D.C.: National Academies Press, 2006.

3. Federal Trade Commission. A Review of Food Marketing to Children and Adolescents: Follow-Up Report. Washington, D.C.: Federal Trade Commission, 2012.

4. Cairns G, Angus K, Hastings G, et al. Systematic reviews of the evidence on the nature, extent and effects of food marketing to children: A retrospective summary. Appetite 2013;62:209-215.

5. Council of Better Business Bureaus. Children's Food and Beverage Advertising Initiative. 2017. Available at https://www .bbb.org/council/the-national-partner-program/national-advertising- 
review-services/childrens-food-and-beverage-advertising-initiative Last accessed May 10, 2017.

6. Council of Better Business Bureaus. Children's Food \& Beverage Advertising Initiative Foods and Beverages that Meet the CFBAI Category-Specific Uniform Nutrition Criteria that May Be in Child-Directed Advertising. 2015. Available at https://www .bbb.org/globalassets/shared/media/cfbai/cfbai-product-list-june2015_final.pdf Last accessed May 10, 2017.

7. Children's Food and Beverage Advertising Initiative. CategorySpecific Uniform Nutrition Criteria. 2011. Available at www .bbb.org/us/storage/16/documents/cfbai/CFBAI-Category-SpecificUniform-Nutrition-Criteria.pdf Last accessed May 10, 2017.

8. Children's Food and Beverage Advertising Initiative. CategorySpecific Uniform Nutrition Criteria, 2nd ed., 2018 White Paper. 2018. Available at https://bbbprograms.org/siteassets/documents/ cfbai/cfbai-white-paper-final-pdf.pdf Last accessed December 16, 2018.

9. World Health Organization. WHO Regional Office for Europe Nutrient Profile Model. Copenhagen, Denmark: WHO. 2015. Available at www.euro.who.int/_data/assets/pdf_file/0005/270716/ Europe-nutrient-profile-model-2015-en.pdf?ua $=1$ Last accessed May 10, 2017.

10. US Department of Agriculture, Agricultural Research Service. USDA Food Composition Databases. Available at https://ndb .nal.usda.gov/ndb Last accessed May 10, 2017.

11. Powell LM, Harris JL, Fox T. Food marketing expenditures aimed at youth: Putting the numbers in context. Am J Prev Med 2013;45: 453-461.

12. Harris JL, Pomeranz JL, Lobstein T, et al. A crisis in the marketplace: How food marketing contributes to childhood obesity and what can be done. Annu Rev Public Health 2009;30:211-225.

13. Center for Science in the Public Interest. Milkshakes, Sugary Cereals, Candy: What Nickelodeon Is Peddling to Kids: A Report. Washington, DC: CSPI. 2016. Available at https://cspinet .org/resource/milkshakes-sugary-cereals-candy-what-nickelodeonpeddling-kids-0 Last accessed May 10, 2017.

14. Kunkel D, McKinley C, Wright P. The Impact of Industry Selfregulation on the Nutritional Quality of Foods Advertised on Television to Children. Oakland, CA: Children Now, 2009.
15. United States Department of Agriculture. WIC Food PackagesRegulatory Requirements for WIC-Eligible Foods. Available at www.fns.usda.gov/wic/wic-food-packages-regulatory-requirementswic-eligible-foods Last accessed May 10, 2017.

16. United States Department of Health and Human Services and United States Department of Agriculture. 2015-2020 Dietary Guidelines for Americans, 8th ed. Washington, DC: USDA/HHS. 2015. Available at http://health.gov/dietaryguidelines/2015/guidelines Last accessed May 10, 2017.

17. Jackson SL, Coleman King SM, Zhao L, et al. Prevalence of excess sodium intake in the United States-NHANES, 2009-2012. MMWR Morb Mortal Wkly Rep 2016;64:1393-1397.

18. Yang Q, Zhang Z, Kuklina EV, et al. Sodium intake and blood pressure among US children and adolescents. Pediatrics 2012;30: 611-619.

19. Centers for Disease Control and Prevention. High Blood Pressure During Childhood and Adolescence. Available at https://www .cdc.gov/bloodpressure/youth.htm Last accessed September 9, 2018.

20. Healthy Eating Research. Better for You Foods: A Guide to Evaluating the Quality of Nutrition Standards. 2018. Availale at https://healthyeatingresearch.org/wp-content/uploads/2018/11/her NutritionStandards_final.pdf Last accessed December 17, 2018.

21. U.S. Department of Agriculture, Food and Nutrition Service. National School Lunch Program and School Breakfast Program: Nutrition standards for all foods sold in school as required by the Healthy, Hunger-Free Kids Act of 2010. Fed Regist 2016;81: 50132-50151.

Address correspondence to: Margo G. Wootan, DSc Center for Science in the Public Interest 1220 L Street NW Suite 300 Washington, DC 20005

E-mail: mwootan@cspinet.org 